\title{
Sensitivity of forests in the European Alps to future climatic change
}

\author{
Harald Bugmann* \\ Systems Ecology, Institute of Terrestrial Ecology, Swiss Federal Institute of Technology Zürich (ETHZ), Grabenstrasse 3, \\ CH-8952 Schlieren, Switzerland
}

\begin{abstract}
Model-based assessments of the impacts of climatic change on forests are confronted with 2 fundamental problems: first, there is a considerable uncertainty in the predictions of future climate; second, the forest models contain simplified parameterizations of ecological processes. In this paper, the sensitivity of forest models to different steady-state climate scenarios, to different process formulations and to different assumptions on the transient behaviour of climate is studied. The effects of 3 scenarios of climatic change and the behaviour of 5 for est gap models of the FORECE/FORCLIM family are compared at sites along an elevational gradient in the European Alps. A wide variety of species compositions may be obtained at a given site depending on the scenario of future climate. At some sites all future forests differ radically from today's forest, suggesting that these current forests are highly sensitive to climatic change. At some sites, the results of the 5 forest models differ strongly with respect to species composition and carbon storage when subjected to the same climate scenario, showing that the models need to be improved in order to arrive at reliable and robust parameterizations of abiotic and biotic influences in forest models. When comparing the effects of step, linear, and sigmoid changes of the mean climatic parameters over $100 \mathrm{yr}$, it becomes evident that the type of change modelled is not crucial because the climatic change proceeds fast compared to the successional dynamics. It is concluded that simulations of the possible effects of climatic change on forests should be considered as sensitivity tests, not as predictions. Given the current uncertainties in atmospheric sciences (climate predictions) and in ecology (modelling of long-term forest dynamics), the most promising research strategy is to compare the effects of several climate scenarios and the projections of several forest models to arrive at state-of-the-art ecological impact assessments.
\end{abstract}

KEY WORDS: Climate change - Sensitivity analysis - Forest gap models - European Alps - Model comparison Species composition

\section{INTRODUCTION}

Forest gap models (Botkin et al. 1972, Shugart 1984) have often been used to assess the possible long-term impacts of future climatic changes on the species composition of forests (e.g. Solomon 1986, Pastor \& Post 1988, Kienast 1991, Bugmann \& Fischlin 1994). Typically, such studies were based on the application of a single forest model, and often only 1 scenario of climatic change was investigated.

Any model-based assessment of the ecological impacts of climatic change is faced with a 2 -fold prob-

\footnotetext{
- Present address: Potsdam Institute for Climate Impact Research, PO Box 601203, D-14412 Potsdam, Germany.

E-mail: bugmann@pik-potsdam.de
}

lem. First, there is a considerable uncertainty inherent in the predictions of future climate on both the global and even more pronounced on the regional scale (Houghton et al. 1990, 1992, Wigley \& Raper 1992). Second, ecological models incorporate different and simplified parametrizations of the processes under consideration (Bonan 1993, Bugmann \& Martin 1995). Consequently, these parametrizations are likely to contain errors on both the quantitative and maybe even on the conceptual level (Solomon 1986, Shugart \& Prentice 1992)

In view of these problems, it appears to be more promising to analyse and compare the behaviour of several ecological models under several scenarios of climatic change instead of focusing on just 1 model and 1 scenario. This approach also emphasizes that such 
studies are tests of the sensitivity to climatic change of forests ecosystems, and not predictions of their future structure and functioning

In this paper, a number of scenarios of climatic change are used to study the response of the tree species composition of forests. For the sake of comparability, the scenarios all refer to the year 2100, and it is assumed that the climatic parameters reached by then can be used to define a new, constant climate. It is undisputed that this assumption is unrealistic because there is no evidence that climatic change would come to a halt by the end of the next century (Houghton et al. 1990, 1992). Again, the simulation results obtained like this do not constitute predictions of the future state of forests in the European Alps, but simply sensitivity tests.

I will address the following questions:

First, let us assume that there was a forest model that we could favour over all the others. How does this model behave when it is exposed to several climate scenarios? How sensitive are the projections obtained from the forest model to the differences between these climate scenarios?

Second, given that there was no uncertainty in the prediction of future climate, i.e. that a climate scenario could be identified unequivocally as the 'best estimate', how does the behaviour of several forest models compare under this climate scenario? Are the projections of the future forest composition sensitive to the assumptions incorporated in the various forest models?

Third, even if we could favour one climate scenario over the others, there is some uncertainty inherent in this scenario. How sensitive are the projections obtained from a forest model to these uncertainties?

Finally, many climate scenarios give us an indication about what the change in a given weather variable will be by a certain point in the future. However, for most scenarios it is not known how this change will be realized. Most impact studies so far have assumed that climate changes linearly (Solomon 1986, Pastor \& Post 1988, Kienast 1991); other authors have studied the response of forest models to an instantaneous climatic change, i.e. its step response (Bugmann \& Fischlin 1994, Fischlin et al. 1995). Thus, how sensitive is the behaviour of forest gap models to the assumptions on the nature of transient climatic change?

\section{MATERIAL AND METHODS}

2.1. Forest gap models. Forest gap models (Botkin et al. 1972, Shugart 1984) are simulators of the population dynamics of trees on small patches of land. Patch size in these models is equivalent to the projected crown size of a large individual tree, so that the death of a mature individual leads to a strong change of the environmental conditions on the patch, thus giving rise to gap-phase dynamics (Watt 1947). Stand development on a forest patch is simulated by calculating establishment, growth, and death of individual trees as a mixture of deterministic and stochastic processes. To obtain forest development at the ecosystem level, the successional patterns of patches from many simulation runs are averaged. This concept is supported by various plant succession studies which show that a forest ecosystem may be described by the average growth dynamics of a multitude of patches with different successional ages (Bray 1956, Curtis 1959, Forman \& Godron 1981).

In gap models, forest dynamics are driven by extrinsic and intrinsic variables of the species and the stand. Typical variables extrinsic to the stand are summer warmth, soil moisture, and browsing. Variables intrinsic to the species are the maximum potential growth rate and mortality, while shading is a variable intrinsic to the stand. Unfavourable environmental factors control the exclusion of species from the establishment process. Growth of individual trees is simulated by decreasing the maximum potential diameter growth rate at its respective age by environmental factors that are less than optimum. The form of the maximum growth equation is similar to a logistic equation; it is based on the assumption that annual biomass increment is proportional to the amount of sunlight the leaves receive (Botkin et al. 1972). Tree mortality is determined by a Poisson process parameterized by allowing only a small fraction of all individuals to reach the maximum physiological age. Furthermore, trees are also removed from the patch if they are growing slowly.

Five forest gap models of the FORECE/FORCLIM family are used in this study:

- Forece, a conventional gap model that was developed for central Europe (Kienast 1987).

- ForClim 1.1, a simplified descendant of Forece comprising only the most fundamental ecological processes (Bugmann \& Fischlin 1994); the formulation of climate-dependent ecological processes in FOrCLIM 1.1 is done in the same way as in FORECE.

- For Clim 1.3, a madel developed from ForCLIM 1.1 by improving the mathematical formulation of the climate-dependent processes (Bugmann \& Fischlin 1994, Fischlin et al. 1995).

- FORCLIM-E/P 2.4, one variant of the FORCLIM model developed by Bugmann (1994, 1996); it differs from FORCLIM 1.3 in the formulation of ecological factors and of climatic influences; like its predecessors, it does not consider belowground carbon/nitrogen dynamics. 
- ForCLIM-E/P/S 2.4, which also incorporates the belowground turnover of carbon and nitrogen (Bugmann 1994, 1996).

2.2. Study sites and steady-state climate scenarios. Six sites along a climatological and an altitudinal gradient in the European Alps were selected for the present study, ranging from above the current alpine timberline (Gotthard) to central alpine valleys close to the dry timberline (Sion; Table 1). The climatic data for these sites were obtained from the Swiss Meteorological Agency (SMA 1901-1990). To obtain a site above the current potential timberline, the monthly means of temperature at the site Gotthard were lowered by $0.7^{\circ} \mathrm{C}$ throughout the year, thus giving rise to the site 'Gotthard II' (Table 1). The other site-specific parameters were adopted from Bugmann (1994).

The scenarios of future climatic change for the year 2100 stem from 3 sources (Table 2). First, a scenario was developed based on the first report of the Intergovernmental Panel on Climate Change (IPCC; Houghton et al. 1990). This scenario was extrapolated from the difference between the regional scenario for

Table 1. Location, elevation, and climatic data of sites in the European Alps used in the present study. $T$ : annual mean temperature; $P$ : total annual precipitation

\begin{tabular}{|lcccrr|}
\hline Name & $\begin{array}{c}\text { Latitude } \\
\left({ }^{\circ} \mathrm{N}\right)\end{array}$ & $\begin{array}{c}\text { Longitude } \\
\left({ }^{\circ} \mathrm{E}\right)\end{array}$ & $\begin{array}{c}\text { Elevation } \\
(\mathrm{m})\end{array}$ & $\begin{array}{c}\mathrm{T} \\
\left({ }^{\circ} \mathrm{C}\right)\end{array}$ & $\begin{array}{c}P \\
\left(\mathrm{~mm} \mathrm{yr}^{-1}\right)\end{array}$ \\
\hline Gotthard II & 46.6 & 8.6 & 2190 & -0.8 & 2162 \\
Bever & 46.6 & 9.9 & 1712 & 1.5 & 841 \\
Davos & 46.8 & 9.8 & 1590 & 3.0 & 1007 \\
Airolo & 46.5 & 8.6 & 1149 & 6.1 & 1616 \\
Bern & 46.9 & 7.4 & 570 & 8.4 & 1006 \\
Sion & 46.2 & 7.4 & 542 & 9.7 & 597 \\
\hline
\end{tabular}

central and southern Europe and the global average scenario for the year 2030 (Table 2). Second, a scenario similar to that used by Kienast (1991) was adapted; the only difference being that Kienast (1991) applied the changes projected for the winter months to the climatic parameters of December through February, whereas in the present study these changes are used to modify the climatic parameters of the 6 'winter' months October through March, which is in accordance with the IPCC practice. Third, regionalized scenarios of climatic change as derived by Gyalistras et al. (1994) for the sites Bever, Davos, and Bern were adapted from Bugmann \& Fischlin (1994). Lacking quantifiable information on the future variability of climate, in all scenarios the variances of temperature and precipitation were assumed not to deviate from the current values.

2.3. Uncertainty inherent in climate scenarios. The quantification of the uncertainty inherent in scenarios of future climate is quite difficult, most notably because there is a wide array of sources of uncertainty. For example, Fischlin et al. (1995) tried to determine the uncertainty of the IPCC scenario (Table 2) based on semi-quantitative reasoning and a number of different sources, but the uncertainty bounds used in their study were still not conclusive. On the other hand, some of the uncertainty inherent in the regionalized scenarios of climatic change has been quantified explicitly by Gyalistras et al. (1994), who calculated not only the means, but also the distribution of the downscaled mean climatic parameters over time. Thus, the regionalized scenarios of climatic change at the sites Bever, Davos, and Bern were selected to study the uncertainty inherent in a given climate scenario (Table 3 ). These uncertainty bounds had already been used in the impact assessment by Bugmann \& Fischlin (1994).

Table 2. Scenarios of climatic change relative to current climate for the year 2100 according to various sources. The 'IPCC' scenario is based on the 'Business-As-Usual' scenario A of fossil fuel emissions. The 'Kienast' scenario is based on steady-state $2 \times \mathrm{CO}_{2}$ GCM runs. The 'Regionalized' scenarios are based on the downscaled trends from an uncorrected 100-year (1986-2085) transient run of the ECHAM GCM for the IPCC 'Business-As-Usual' scenario A (Cubasch et al. 1992). Bold face denotes those scenarios used in the present study

\begin{tabular}{|c|c|c|c|c|c|}
\hline Scenario & $\begin{array}{c}T_{\text {summer }} \\
\left({ }^{\circ} \mathrm{C}\right)\end{array}$ & $\begin{array}{c}P_{\text {summer }} \\
\left(\mathrm{cm} \mathrm{mo}^{-1}\right)\end{array}$ & $\begin{array}{l}T_{\text {winter }} \\
\left({ }^{\circ} \mathrm{C}\right)\end{array}$ & $\begin{array}{c}P_{\text {winter }} \\
\left(\mathrm{cm} \mathrm{mo}^{-1}\right)\end{array}$ & Source ${ }^{a}$ \\
\hline IPCC, 2030 (global) & +1.5 & + a few $\%$ & +1.5 & + a few $\%$ & 1 \\
\hline IPCC, 2030 (C. Europe) & +2.5 & $-15 \%$ & +1.5 & - & 1 \\
\hline IPCC, 2100 (global) & +3.7 & - & +3.7 & - & 1 \\
\hline IPCC, 2100 (C. Europe) & +4.7 & - & +3.7 & - & 1 \\
\hline Kienast & +3.0 & $+10 \%$ & +3.5 & $+10 \%$ & 2 \\
\hline Regionalized, Bern & +2.64 & +3.98 & +3.76 & +3.13 & 3 \\
\hline Regionalized, Davos & +3.28 & +0.91 & +3.00 & +2.14 & 3 \\
\hline Regionalized, Bever & +4.16 & +3.82 & +1.48 & +2.54 & 3 \\
\hline
\end{tabular}


Table 3. Uncertanty inherent in the regionalized scenarios of climatic change (Table 2), expressed as twice the standard deviation $(2 \sigma)$ of the downscaling models (Gyalistras et al. 1994)

\begin{tabular}{|lcccc|}
\hline Site & $\begin{array}{c}T_{\text {summer }} \\
\left({ }^{\circ} \mathrm{C}\right)\end{array}$ & $\begin{array}{c}P_{\text {summer }} \\
\left(\mathrm{cm} \mathrm{mo}^{-1}\right)\end{array}$ & $\begin{array}{c}T_{\text {winter }} \\
\left({ }^{\circ} \mathrm{C}\right)\end{array}$ & $\begin{array}{c}P_{\text {winter }} \\
\left(\mathrm{cm} \mathrm{mo}^{-1}\right)\end{array}$ \\
\hline Bern & \pm 1.21 & \pm 3.96 & \pm 1.33 & \pm 1.72 \\
Davos & \pm 0.74 & \pm 1.95 & \pm 1.26 & \pm 3.18 \\
Bever & \pm 1.59 & \pm 2.39 & \pm 0.94 & \pm 1.20 \\
\hline
\end{tabular}

2.4. Transient climatic changes. It is a common practice in systems theory to explore the response of a system to a step change in the input data (Fig. 1). On the other hand, most of the previous impact assessments using forest gap models have adopted a linear change of the mean climatic parameters over time (e.g. Solomon 1986, Pastor \& Post 1988, Kienast 1991). In reality, climatic change will follow neither of these assumptions, and a more gradual, e.g. sigmoid, change would be more likely to occur. Thus, these 3 types of climatic changes were compared in the present study (Fig 1).

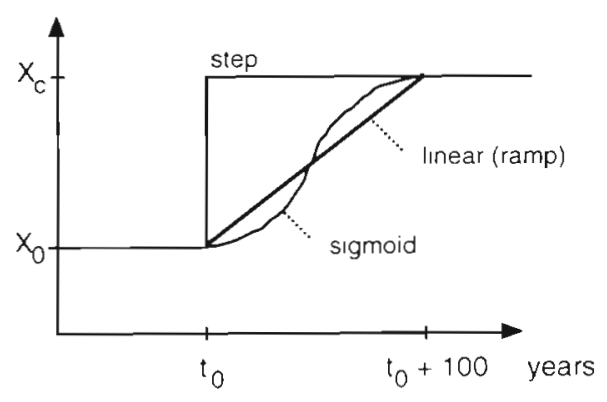

Fig. 1. Three types of transient climatic change explored in this study. $\mathrm{X}_{0}$ : long-term mean value of a climatic variable (e.g. average of July temperature) under current climatic conditions; $X_{c}$ : long-term mean value of the variable under the climatic change scenario

2.5. Simulation experiments. To explore the behaviour of 1 forest model under various climate scenarios, the model ForCLIM-E/P 2.4 (Bugmann 1994, 1996) was selected. At each of the sites Bever, Davos, and Bern, all 3 climate scenarios were used. At the other sites, only the Kienast scenario and the IPCC scenario were available. The analysis concentrated on the steady-state species compositions, which were estimated under current and under the future climate using a new, efficient simulation technique based on one single simulation run by sampling $\mathrm{n}=200$ points in time with a sampling distance of $\Delta t=150$ yr (Bugmann 1997a).

The behaviour of the 5 gap models was compared using the regionalized climate scenarios (Table 2).
They bear the advantage of providing a picture of possible future climate that is consistent with global climate change as projected by General Circulation Models (GCMs) and with measurements of the variations of temperature and precipitation at the respective locations. Due to implementational limitations of some of the models, the equilibrium species composition of the forest models was estimated either as outlined above or by averaging the output from transient simulations over 500 yr (Bugmann \& Fischlin 1994).

The ecological effects of the uncertainty inherent in the regionalized scenarios were explored with the model ForCLIM-E/P 2.4. The steady-state species compositions were estimated using a single run and sampling $\mathrm{n}=200$ points with $\Delta t=150$ yr (Bugmann 1997a).

To analyse the effects of various assumptions on transient climatic change, the regionalized scenarios and the FORCLIM-E/P model were used, and 200 patches were simulated for $1500 \mathrm{yr}$, starting from bare ground. This long simulation period is required so that the model can reach the steady state both under the current and the future climate (Bugmann et al. 1996a): during the first $800 \mathrm{yr}$ the models were allowed to reach the steady-state species composition under current climate; then the transient climatic change was applied, and after year 900 the future climate was assumed to be constant until the end of the simulation. For the step scenario, the climatic change was assumed to take place in the simulation year 800 .

To compare the different estimates of the steady states, a percentage similarity coefficient (Eq. 1) was used; it relates any 2 data sets $X=\left\{x_{1}, x_{2}, \ldots, x_{n}\right\}$ and $\mathbf{Y}=\left\{y_{1}, y_{2}, \ldots, y_{\mathrm{n}}\right\}$ as follows:

$$
P S=1-\frac{\sum_{i=1}^{n}\left|x_{i}-y_{i}\right|}{\sum_{i=1}^{n}\left(x_{i}+y_{i}\right)}
$$

where $0 \leq P S \leq 1$ (Prentice \& Helmisaari 1991). This coefficient can be interpreted as the fraction of values common to both sets of data. It offers the following advantages: not only does it track differences in the relative distributions of the $x_{1}$ and $y_{1}$ values (e.g. species-specific biomasses), but it also declines the larger the difference between the sums $\Sigma x_{1}$ and $\Sigma y_{1}$ (e.g. total biomass) becomes. Bugmann (1997a) found that 2 species compositions simulated by gap models under European conditions can be considered to be significantly $(\alpha=5 \%)$ different from each other if $P S<0.85$, given that the compositions are estimated from 200 samples of one single simulation run with a sampling interval of $150 \mathrm{yr}$

Plant nomenclature throughout the paper is according to Hess et al. (1980). 


\section{RESULTS AND DISCUSSION}

\subsection{Behaviour of ForCLIM-E/P 2.4 under various scenarios of climatic change}

The simulation studies with FORCLIM-E/P 2.4 reveal that there is no uniform response of the model across the 6 sites (Fig. 2). All the steady states at a given site are significantly different from each other $(\alpha=5 \%$; cf. Bugmann 1997) except for the comparison between the IPCC and Kienast scenario at the site Airolo, where the percentage similarity coefficient (PS, Eq. 1) is 0.91 , and the comparison between the Kienast and the regionalized scenario at the site Bern ( $P S=0.93)$. The effects of the various scenarios on the simulated steady-state species composition are discussed for each site in turn:

At the site Bever (Fig, 2), there is hardly any agreement among the simulated forests under climatic change. The projections under the various climate scenarios range from Norway spruce-maple (Picea excelsaAcer spp.) forests under the regionalized scenario, which resemble those typical of today's montane belt (Ellenberg \& Klötzli 1972), to species compositions as surprising as silver fir-chestnut-oak (Abies alba-Castanea sativa-Quercus spp.) forests under the IPCC scenario. However, there is 1 pattern that is common to all scenarios of future climate. All these steady-state species compositions differ radically from the species composition simulated under current climatic conditions, which is also typical of the actual vegetation at Bever Thus, sites like Bever are likely to undergo drastic changes, but it appears to be impossible to give an indication of what the exact changes will be, even if we optimistically assume that the forest model does not contain any uncertainties.

At the site Gotthard II (Fig. 2), both scenarios agree that (1) the timberline will rise and this area would become afforested, and (2) Norway spruce Picea excelsa would come to dominate these forests. However, the 2 scenarios produce diverging results concerning the abundance of species such as silver fir Abies alba and European larch Larix decidua. Comparing these findings to the results published by Kienast (1991), who used the FORECE model, a large discrepancy becomes evident: In the Kienast study, Pinus cembra was abundant after the first $100 \mathrm{yr}$ of climatic change, which most probably represents an anomaly (cf. Bugmann 1996). Additionally, the forests simulated in that study had very low biomass (around $100 \mathrm{tha}^{-1}$ ) irrespective of the magnitude of climatic change, whereas ForCLIM simulates an aboveground biomass of almost $300 \mathrm{t} \mathrm{ha}^{-1}$ (Fig 2). The low biomass obtained from FORECE is probably an artifact of the prescribed maximum aboveground biomass, which produces inconsistent results under climatic change (Bugmann 1994, 1996, Fischlin et al. 1995).

At the site Davos (Fig. 2), all 3 climate scenarios induce a shift from the subalpine Norway spruce Picea excelsa forests prevailing today to forests where silver fir Abies alba, Norway spruce, and European beech Fagus silvatica are abundant. Thus, the model predicts an invasion of species that are typical of today's montane belt (Ellenberg \& Klötzli 1972). Again, there are
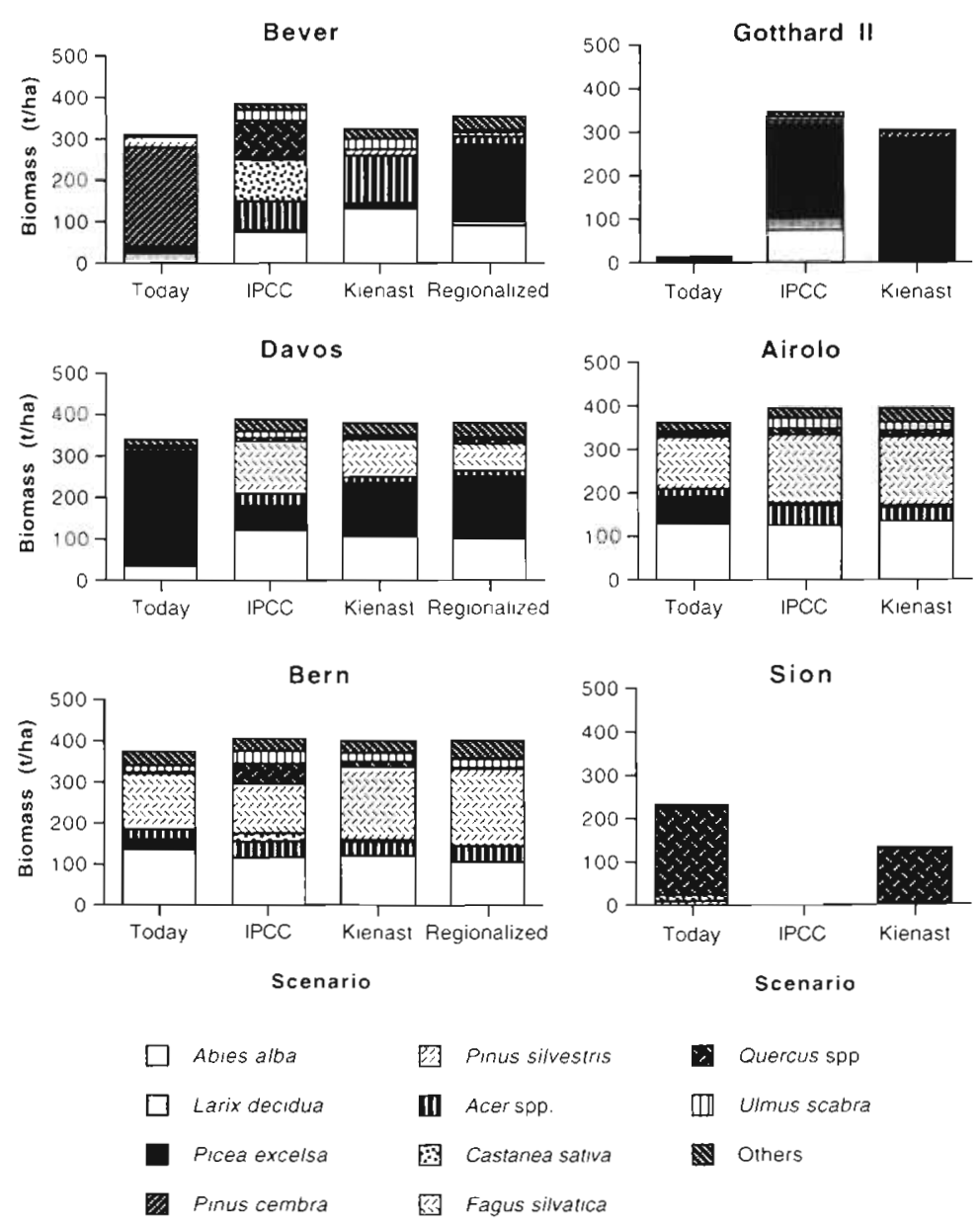

Quercus spp

III Uimus scabra

Others

Fig. 2. Steady-state species composition simulated by the model ForCLIME/P 2.4 under various climate scenarios (Table 2) along a climate gradient

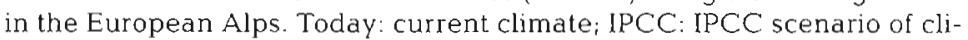
matic change; Kienast: climate scenario as used by Kienast (1991) for the year 2100; Regionalized: regionalized climate scenario obtained by the downscaling methodology (Gyalistras et al. 1994) 
some differences among the various scenarios concerning the abundance of single species.

At the site Airolo (Fig. 2), Norway spruce Picea excelsa, which is characteristic of montane mixed forests, is replaced by silver fir Abies alba, European beech Fagus silvatica, and other deciduous species under both climate scenarios. Comparing these results to the ones by Kienast (1991) is difficult because of the large sensitivity to species parameters of the FORECE model (cf. Bugmann 1994), and further studies with the FORECE model would be required to allow for a meaningful comparison.

At the site Bern (Fig. 2), only slight changes occur as compared to current climatic conditions. The major features of the current forests, especially the dominance of beech Fagus silvatica and silver fir Abies alba, remain characteristic also of future forests; under all scenarios, similar forest compositions are obtained.

At Sion, major differences become evident concerning the physiognomy of the site under climatic change: While the IPCC scenario leads to steppification, a scrawny, low-biomass forest continues to exist under the Kienast scenario (Fig. 2). Using ForecE, Kienast (1991) found that steppification may occur within $50 \mathrm{yr}$ after the onset of climatic change. Hence, according to these simulation studies there is a considerable risk that sites close to the dry timberline may be confronted with forest dieback phenomena and steppification under climatic change

\subsection{Behaviour of 5 gap models under regionalized scenarios}

The simulation results from the 5 gap models at the sites Bever, Davos, and Bern are shown in Fig. 3. At the site Bever, the models produce strongly differing species composition under this scenario of climatic change. While the percentage similarity coefficient (PS, Eq. 1) between ForCLIM-E/P and E/P/S is 0.75, and $P S=0.85$ between FORCLIM 1.1 and 1.3, there is little resemblance between these 2 groups and the ForECE species composition ( $P S<0.4$ ). At the site Davos, there are also considerable differences among the models, but they are more gradual than at Bever. The forest composition at the low-elevation site Bern exhibits the smallest differences among the 5 models (Fig. 3).

However, although species compositions differ less as elevation decreases, there is a large disagreement on total aboveground biomass between ForCLIM-E/P(/S) and the other 3 models at all 3 sites both under current climate (results not shown) and under the scenarios of climatic change (Fig. 3). At Bern, the difference of total aboveground biomass leads to low PS coefficients although the simulated species composition is rather sim-
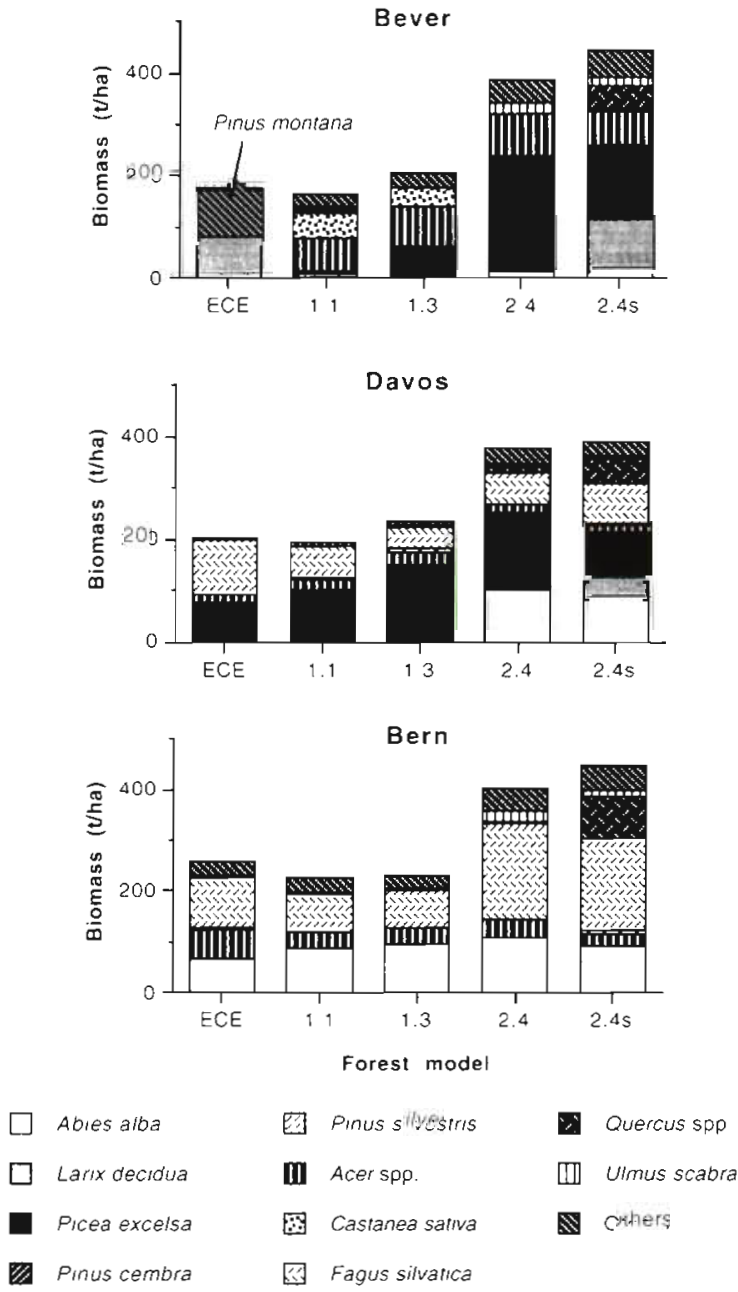

Fig. 3. Steady-state species compositions as simulated by various forest gap models under the same scenario of climatic change obtained by the downscaling methodology (Table 2). ECE: FORECE model (Kienast 1987); 1.1. ForClim version 1.1 (Bugmann \& Fischlin 1994); 1.3: ForCLIM version 1.3 (Bugmann \& Fischlin 1994); 2.4: FORCLM-E/P, version 2.4 (Bugmann 1994, 1996); 2.4s: ForCLIM-E/P/S, version 2.4 (Bugmann 1994, 1996)

ilar among the forest models (e.g. between ForCLIM 1.3 and FORCLIM-E/P PS =0.57, between FORCLIM-E/P and FOrCLIM-E/P/S $P S=0.82$ ). Thus, we may conclude that the models are sensitive to the formulation of ecological factors especially when simulating subalpine forests (cf. Bugmann \& Fischlin 1994).

This sensitivity poses a serious problem because there are no a priori ways of determining which of the 5 gap models is 'best' We simply lack appropriate ecological knowledge on the factors determining the establishment, growth, and mortality of forest trees, and in each model other, generally justifiable assumptions are made. If we are to achieve forest models that are capable of projecting long-term forest dynamics more 
reliably, research in at least 3 areas is required: (1) long-term monitoring and experimentation on the effects of climate and $\mathrm{CO}_{2}$ on demographic processes in forests should be conducted, which contrasts the current emphasis on short-term investigations dealing

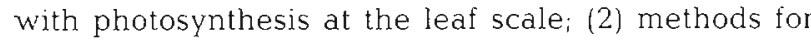
translating ecological research results across scales in time and space need to be further elaborated; and (3) the concept of using empirical relationships for many environmental effects on demographic processes should be abandoned in gap models. It is likely that new concepts can be introduced into these models that make many of the old approaches obsolete and that have far fewer shortcomings.

\subsection{Sensitivity of ForClum to uncertainty inherent in regionalized scenarios}

For the sites Bern and Davos, where the different climate scenarios did not lead to large differences in the simulated forest community, there is also little sensitivity to the uncertainty inherent in 1 climate scenario: At Davos, the smallest PS between the species composition simulated under the 'best estimate' regionalized scenario (Table 2) and those simulated under the scenarios corresponding to the lower and upper end of the uncertainty range (Table 3 ) is 0.73 , and the average $P S$ is 0.82 . At Bern, the smallest $P S$ is 0.84 , while the average $P S$ is 0.89 . At the site Bever, however, accounting for the uncertainty inherent in the regionalized scenario produces a wide array of forest composi-

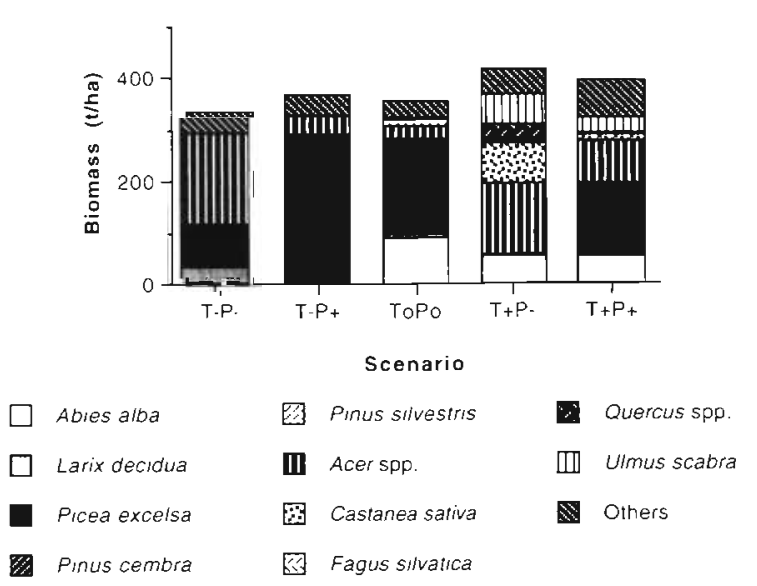

Fig. 4. Effect of the uncertainty inherent in the regionalized climate scenario (Table 3 ) at the site Bever on the steady-state species composition as simulated by the forest model FOrCLIME/P 2.4. $T_{0}, P_{0}$ : best estimate change of temperature and precipitation (Table 2); $\mathrm{T} \pm, \mathrm{P}_{ \pm}$: lower and upper end of uncertainty range for temperature and precipitation, respectively $\left(X_{ \pm}=\right.$ $X_{0} \pm 2 \sigma_{x}$, where $X \in\{T, P\} ;$ cf. Table 3$\}$ tions (Fig. 4): The lowest PS is 0.25 , and the average PS amounts to 0.51 only. Thus, some of the simulated forests have almost nothing in common (Fig. 4).

In addition to the large differences in the simulated species composition, the simulated total aboveground biomass varies from $338 \mathrm{tha}^{-1}$ in the scenario $\mathrm{T}-\mathrm{P}$ (Fig 4) to $419 \mathrm{t}_{\text {ha }}{ }^{1}$ (scenario $T+\mathrm{P}-$ ). Hence, there is also a large uncertainty concerning the aboveground carbon storage of these potential future forests. These results qualitatively corroborate the findings by Fischlin et al. (1995), which were based on the IPCC scenario for the year 2030 .

\subsection{Sensitivity of ForClim to assumptions on the course of transient climatic change}

The transient simulation results based on scenarios of step, ramp, and sigmoid climatic change reveal that there are no large differences at any site (cf. Bugmann $1997 \mathrm{~b})$. At the site Bever, the largest differences between the 3 scenarios of transient climatic change occur (Fig. 5). This is because at Bever the difference between the steady-state species compositions under
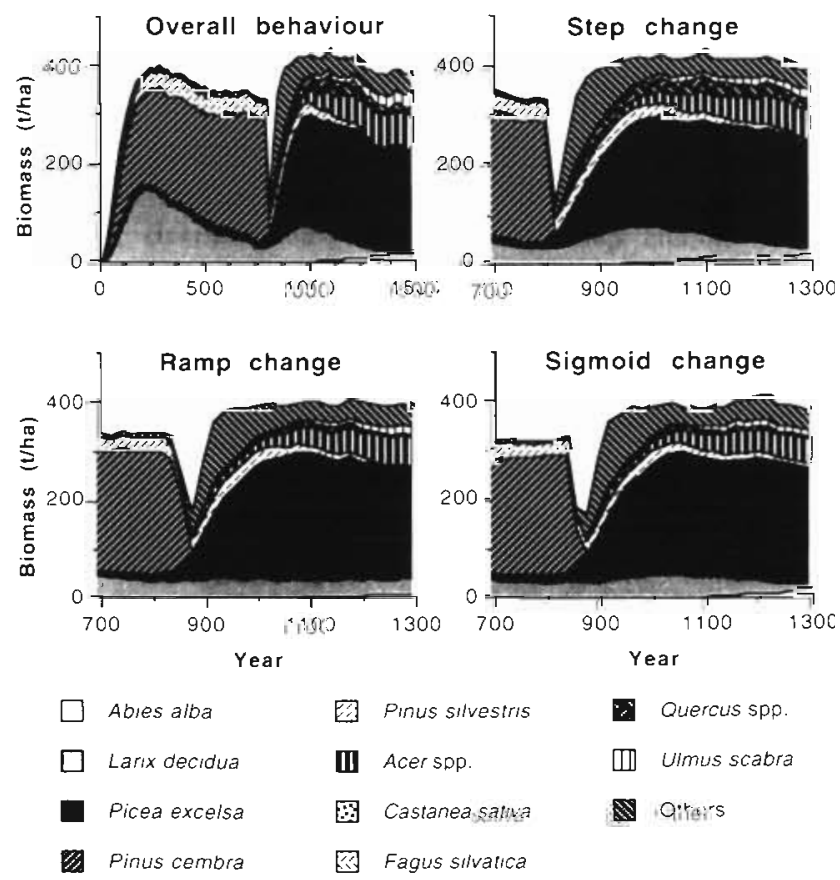

Fig. 5. Effect of various assumptions about the nature of transient climatic change (cf. Fig. 1) on the behaviour of ForCLIME/P 2.4 at the site Bever (cf. Fig. 4). Top left: behaviour of the model under the step change scenario for the full simulation experiment. Excerpts from the simulation results between the years 700 and 1300 are shown for the step change scenario (top right), the ramp change scenario (bottom left) and the sigmoid change scenario (bottom right) 
current climate and under the regionalized scenario of climatic change is larger than at the other sites (Fig. 2).

The evaluation of the percentage similarity $\left(P S_{t}\right)$ coefficients from the simulation years $t=700$ through $t=1300$ suggests that there is a short period (from the years 820 to 860 ) where the disagreement between the step and the ramp scenario is large $\left(P S_{840}=0.33\right)_{i}$ this is due to the fact that in the step scenario the breakdown of the current forest community takes place immediately after the year 800 , whereas in the ramp scenario it starts a few decades later and proceeds more gradually. The fast breakdown of the community in the step scenario increases light availability markedly, which enables the establishment and enhanced growth of light-demanding species like Larix decidua and Quercus robur; however, these species do not become dominant and are outcompeted during the following centuries.

On the other hand, there is hardly any difference between the species composition simulated with the ramp and the sigmoid scenario ( $P S=0.84$ in the year 860 , in all other years $P S>0.93$ ). Thus, for a climatic change of the anticipated magnitude taking place during the relatively short time of 1 century, assumptions about how the climate changes are not important because such a climatic change proceeds fast compared to successional dynamics. Only the assumptions about the level of a hypothesized future constant climate are crucial (Fig. 5; cf. Bugmann 1997b)

\section{CONCLUSIONS}

Most studies of the possible impacts of climatic change on the tree species composition of forests were based on the application of a single forest model under only 1 scenario of future climate, assuming a given time course of climatic change (e.g. Solomon 1986, Kienast 1991). These studies are certainly useful and have come at a good time. Implicitly, such a setup entails 3 assumptions that have not yet been examined: first, that the various projections of future climatic change agree reasonably closely, or that the forest models are not sensitive to the differences between the climate projections; second, that the forest models are robust and reliable enough that the variations between models are insignificant; and third, that the choice of the exact time course of climatic change within a time span of $100 \mathrm{yr}$ is unimportant for model behaviour.

The present paper aimed at testing these assumptions using 5 members of the FORECE/FORCLIM family of forest models and a number of climate scenarios for the European Alps, defined to represent a hypothetical constant climate at the end of the 21 st century.

\subsection{Choice of steady-state climate scenario}

From the comparison of the behaviour of FORCLIM-E/P 2.4 under various scenarios of climatic change at sites along an elevational gradient it becomes evident that widely differing species compositions may be obtained. This suggests that the choice of the climate scenario often is crucial in ecological impact assessments, and that a comparison of the effects of several climate scenarios may be most appropriate (e.g. Lauenroth 1996).

On the other hand, the species composition simulated under the future climates at sites close to the alpine and the dry timberline differs markedly from the one simulated under current climatic conditions, and this pattern is independent of the climate scenario chosen. Sites at mid-altitudes show smaller and more uniform changes of their species composition across the various climate scenarios. Hence sites close to major ecotones, such as the alpine (cold) and the dry timberlines, appear to be most sensitive to climatic change (cf. Bugmann \& Fischlin 1994).

The uncertainty inherent in the regionalized scenario of climatic change leads to a wide array of possible future forest compositions. Thus, even if 1 climate scenario could be identified as the 'best estimate', its uncertainty would still preclude precise statements about future forest composition and aboveground carbon storage, especially at subalpine sites.

\subsection{Choice of forest model}

Similar effects are visible when evaluating the response of various forest models to 1 specific scenario of climatic change: The species composition simulated close to the alpine timberline varies considerably depending on the forest model used, i.e. on the number of factors incorporated in a model and their formulation. It is surmised that the same is valid also for sites close to the dry timberline, but this was not investigated in the present study. Again, sites at mid-altitudes appear to be less sensitive to the choice of the forest model. Striking differences are also visible regarding the aboveground carbon storage simulated by the different models.

It appears that considerable research efforts are required to arrive at forest models that contain reliable parameterizations of the influence of biotic and abiotic processes on long-term forest dynamics, involving a revision of the approach taken in the models as well as longterm monitoring and experimentation on demographic processes in forests. In the meantime, the sensitivity of forest models to the formulation of these processes suggests that model comparisons are an indispensable tool for interpreting the results of impact studies (cf. Bugmann \& Martin 1995, Bugmann et al. 1996b). 
In addition, note that the 5 gap models have been developed to yield similar species composition under current climate at a wide range of sites in the European Alps, but they still produce large differences when applied in a changed climate. This points at the need of testing and comparing models not only under current climate, but also under conditions different from those of today (e.g. Bugmann \& Martin 1995, Fischlin et al. 1995. Hänninen 1995, Bugmann et al. 1996b).

\subsection{Choice of transient change scenario}

The comparison of the effects of step, linear (ramp), and sigmoid climatic changes during 100 yr show that the choice of the transient scenario indeed is not crucial because the change of the abiotic conditions proceeds fast compared to the successional dynamics. However, if climatic change continues for several centuries, i.e. when the time scale of climatic change appraaches the time scale of forest succession (Bugmann \& Fischlin 1994), the differences between the various scenarios of transient climatic change would certainly be more pronounced; as mentioned in Section 1, there is no evidence that climatic change in reality would come to a halt by the end of the next century. Moreover, these findings may not hold for changes of the variability of climatic parameters, which have not been investigated here.

It may be daunting to see that there is a large uncertainty inherent in the climate projections for any specific region such as the European Alps, which then feeds into the uncertainty and at the same time strong sensitivity of forest gap models. Hence, one may be tempted to conclude that there is nothing we can learn from experiments such as the ones presented in this paper, and that all the results are wrong. However, irrespective of the climate scenario and the specific version of forest model used, the simulations show that some forests appear to be very sensitive to changing climatic parameters. For example, at the site Bever all forests simulated by any model under any scenario of climatic change differ strongly from the forest simulated under current conditions. Hence, instead of wanting to 'predict' or even 'forecast' the future fate of specific forests, it may be more fruitful to determine the sensitivity to global change of current forests, and in this exercise gap models can play an important role.

Acknowledgements. This study is based on the author's doctoral dissertation submitted to the Swiss Federal Institute of Technology Zürich (ETHZ). The advice by Andreas Fischlin. and Hannes Flühler of the Institute of Terrestrial Ecology ETHZ as well as the financial support of ETHZ are gratefully acknowledged.

\section{LITERATURE CITED}

Bonan GB (1993) Do biophysics and physiology matter in ecosystem models? Clim Change 24:281-285

Botkin DB, Janak JF, Wallis JR (1972) Some ecological consequences of a computer model of forest growth. J Ecol 60 : $849-872$

Bray JR (1956) Gap-phase replacement in a maple-basswood forest. Ecology 37:598-600

Bugmann $H$ (1994) On the ecology of mountainous forests in a changing climate: a smulation study. PhD thesis no. 10638, Swiss Federal Institute of Technology Zurich

Bugmann H (1996) A simplified forest model to study species composition along climate gradients. Ecology 77 : $2055-2074$

Bugmann H (1997a) An efficient method for estimating the steady state species composition of forest gap models. Can $\mathrm{J}$ For Res 27 :in press

Bugmann $H$ (1997b) Gap models, forest dynamics and the response of vegetation to climate change. In: Huntley $B$, Cramer W, Morgan AV, Prentice HC, Allen JRM (eds) Past and future rapid environmental changes: the spatial and evolutionary responses of terrestrial biota. Springer-Verlag, Berlin, p 441-453

Bugmann H, Fischlin A (1994) Comparing the behaviour of mountainous forest succession models in a changing climate. In: Beniston $M$ (ed) Mountain environments in changing climates. Routledge, London, p 204-219

Bugmann H, Martin Ph (1995) How physics and biology matter in forest gap models. Clim Change 29:251-257

Bugmann H, Fischlin A, Kienast F (1996a) Model convergence and state variable update in forest gap models. Ecol Model 89:197-208

Bugmann HKM, Yan X, Sykes MT, Martin Ph, Lindner M, Desanker PV. Cumming SG (1996b) A comparison of forest gap models: model structure and behaviour Clim Change 34:289-313

Cubasch U, Hasselmann K, Höck H, Maier-Reimer E, Mikolajewicz U, Santer B, Sausen R (1992) Time-dependent greenhouse warming computations with a coupled oceanatmosphere model. Clim Dyn 8:55-69

Curtis JT (1959) The vegetation of Wisconsin. Univ of Wisonsin Press, Madison

Ellenberg H, Klötzli F (1972) Waldgesellschaften und Waldstandorte der Schweiz. Mitt Eidg Anst Forstl Versuchswes 48:587-930

Fischlin A, Bugmann H, Gyalistras D (1995) Sensitivity of a forest ecosystem model to climate parametrization schemes. Environ Pollut 87:267-282

Forman RTT, Godron M (1981) Patches and structural components for a landscape ecology. BioSci 31:733-740

Gyalistras D, Storch H von, Fischlin A, Beniston M (1994) Linking GCM generated climate scenarios to ecosystems: case studies of statistical downscaling in the Alps. Clim Res 4:167-189

Hänninen $H$ (1995) Assessing ecological implications of climatic change: can we rely on our simulation models? Clim Change 31:1-4

Hess HE, Landolt E, Hirzel R (1980) Flora der Schweiz, 4 vols, 2nd edn. Birkhäuser, Basel

Houghton JT, Callander BA, Varney SK (eds) (1992) Climate change 1992 - the supplementary report to the IPCC scientific assessment. Report prepared for IPCC by Working Group 1. Cambridge Univ Press, Cambridge

Houghton JT, Jenkins GJ, Ephraums JJ (eds) (1990) Climate change - the IPCC scientific assessment. Report prepared 
for IPCC by Working Group 1. Cambridge Univ Press, Cambridge

Kienast F (1987) FORECE - a forest succession model for southern cen:ral Europe. ORNL/TM-10575, Oak Ridge National Laboratory, Oak Ridge, TN

Kienast $F$ (1991) Simulated effects of increasing $\mathrm{CO}_{2}$ on the successional characteristics of Alpine forest ecosystems. Landsc Ecol 5:225-238

Lauenroth WK (1996) The application of patch models to evaluate the potential impacts of a climate change on terrestrial vegetation: an introduction. Clim Change 34: $155-160$

Mitchell JFB (1983) The seasonal response of a general circulation model to changes in $\mathrm{CO}_{2}$ and sea temperatures. $\mathrm{QJ}$ R Meteorol Soc 109:113-152

Mitchell JFB, Lupton G (1984) A $4 \times \mathrm{CO}_{2}$ integration with prescribed changes in sea surface temperatures. Prog Biometeorol 3:353-374

Pastor J, Post WM (1988) Response of northern forests to $\mathrm{CO}_{2}$ induced climate change. Nature 334:55-58

Prentice IC, Helmisaari H (1991) Silvics of north European trees: compilation, comparisons and implications for forest

Editor: G. Esser, Gießen, Germany succession modelling. For Ecol Manage 42:79-93

Shugart HH (1984) A theory of forest dynamics. The ecological implications of forest succession models. Sprınger-Veralg, New York

Shugart HH, Prentice IC (1992) Individual-tree-based models of forest dynamics and their application in global change research. In: Shugart $\mathrm{HH}$, Leemans $\mathrm{R}$, Bonan GB (eds) A systems analysis of the global boreal forest. Cambridge Univ Press, Cambridge, p 313-333

SMA (Swiss Meteorological Agency), (1901-1990) Annalen der Schweizerischen Meteorologischen Anstalt. SMA, Zürich

Solomon AM (1986) Transient response of forests to $\mathrm{CO}_{2}-$ induced climate change: simulation modeling experiments in eastern North America. Oecologia 68:567-579

Watt AS (1947) Pattern and process in the plant community J Ecol 35:1-22

Wigley TML, Jones PD (1988) A climate scenario for Europe. European Conference on Landscape Ecological Impacts of Climatic Change. LICC secretariat, Utrecht

Wigley TML, Raper SCB (1992) Implications for climate and sea level of revised IPCC emissions scenarios. Nature 357 $293-300$

Manuscript first received: July 8, 1996

Revised version accepted: December 10, 1996 